\title{
A Comparison of BCM with BBCM
}

\author{
Wei-Cheng Cui ${ }^{1,2 *}$ \\ ${ }^{1}$ School of Engineering, Westlake University, China \\ ${ }^{2}$ Shanghai Engineering Research Center of Hadal Science and Technology, Shanghai Ocean University, China
}

Submission: April 24, 2019; Published: May 06, 2019

"Corresponding author: Weicheng Cui, Chair professor at Westlake University, China and adjunct professor at Shanghai Ocean University, China

\begin{abstract}
The Big Bang cosmological model (BBCM) is currently the most prevailing cosmological model for the observable universe but it still exists many un-answered questions such as the existence of the Singularity and the reason for a sudden explosion. BBCM is completely based on the materialism ideology which suffers from many paradoxes. In order to resolve these paradoxes, the present author recently proposed a novel cosmological model based on Buddhist philosophy and thus it is called Buddhist cosmological model (BCM). The purpose of this paper is to carry out a detailed comparison between these two models. Through this comparison, one can find the fundamental reasons why these paradoxes exist in BBCM.
\end{abstract}

Keywords: Universe; Cosmology; Big-Bang Cosmological Model (BBCM); Buddhist Cosmological Model (BCM); Comparison

\section{Introduction}

Today, the most prevailing cosmological model for the observable universe is the Big Bang cosmological model (BBCM) [1]. The Big Bang hypothesis states that all the current and past matter in the Universe came into existence at the same time, roughly 15 billion years ago. At this time, all matter was compacted into a very small ball with infinite density and intense heat called a Singularity. Suddenly, the Singularity began expanding, and the universe as we know it began. This model has been confronted to a variety of observations that allow one to reconstruct its expansion history, its thermal history and the structuration of matter. In order to explain new phenomena observed, new concepts such as Dark Matter (DM) and Dark Energy (DE) have been introduced, but after many decades of search, there is no clue what DM and DE are $[2,3]$. pointed out that at least two obvious questions exist in the Big-Bang model.

The first question remained as to how the matter and energy were in this superdense elementary particle? The second question arose from the insolvency of ideas about the explosion of a kind of "cosmic egg", which was the explosion of the largest nuclear bomb. This point of view boils down to the assertion that "space" exploded, and not a material object. At the same time, the authors of this idea do not bother explaining what they think is a "space" and what can explode in an empty space? Therefore, many people are still working on the improvement of the Big-Bang model or the construction of other totally new cosmological models.
All the modern sciences including the BBCM are based on the materialism which holds that matter is the fundamental substance in nature, and that all things, including mental aspects and consciousness, are by-products or epiphenomena of material processes without which they cannot exist. According to this doctrine the material creates and determines consciousness, not vice versa. Now this philosophy cannot explain many life phenomena, e.g. [4,5] has discussed in quite detail about the ten dogmas of modern science based on materialism and some people even claim that it is the time now to end the materialism, e.g. [6]. The most difficult question for the materialism believers is how the first matter comes from and what is the source of forces which cause every object to move in the universe.

In order to resolve these paradoxes, a novel cosmological model based on Buddhist philosophy was recently proposed by the present author [7] and therefore, we call this model as the Buddhist Cosmological Model (BCM). From this author's judgement, BCM seems conceptually clear and logically consistent and it can explain many phenomena which belongs to the frontier problems of modern sciences. The purpose of this paper is to carry out a detailed comparison between BCM and BBCM and wish to bring the discussion to this important question further. The whole paper is divided into five sections. Section 2 summarizes the paradoxes about the materialism and BBCM. Section 3 summarizes the main points of BCM. Section 4 gives a detailed comparison between two 
models in a table format. Finally, section 5 makes a summary and draws some conclusions.

\section{$\mathrm{BBCM}$ and its paradoxes}

Following Karl Popper's famous opinion, "All science is cosmology, I believe", that is why I start my discussion from cosmology. Cosmology is intrinsically linked with mythology and religion as a quasi-rational elaboration of the former. As is wellknown, the Big Bang theory is still the currently most prevailing cosmological model for the observable universe [1], but it still exists many un-answered questions such as the existence of the Singularity and the reason for a sudden explosion. It is wellknown that BBCM is based on materialism in which it is stated that matter is the fundamental substance in nature, and that all things, including mental aspects and consciousness, are results of material interactions [5]. With this philosophical monism, many paradoxes can be found, and the most famous ones are Zeno's paradoxes [8]. From my point of view, the most difficult problem should be the "creator problem" [9].

How was the first matter created and where did the force come from for creating this matter? This problem also exists in the modern string theory such as what are the strings in the universe and who makes them vibrate? [10]. As a matter of the fact, since the discovery of Einstein's famous equation, $E=\mathrm{mC}^{2}$, it has already been proved that the fundamental assumption made in materialism is wrong since matter can be transformed into energy. Schramm [11] has pointed out that very few physical theories are in such a paradoxical situation as Big-Bang cosmology which is completely based on materialism. In this monism, there are no clear definitions of matter and consciousness. In order to explain the redshift phenomenon observed, concepts such as dark matter and dark energy had to be introduced [12], but we are still unclear what they are after many decades' research [2,13]. Frank Wilczek [12] has optimistically told us that in theoretical physics, paradoxes are good, and paradoxes focus our attention, and make us think harder.

This is also true for me why I started to doubt the materialism. Through reading, I have found many criticisms to materialism, e.g. [5,6]. Due to this reason, I has made a comparison of different philosophies and found that only Buddhist philosophy can match the logical consistency requirements of modern sciences and so I constructed a parallel cosmological model based on Buddhist philosophy (Buddhist cosmological model, BCM) in replacing the Big-Bang cosmological model (BBCM) [7]. I found that BCM can overcome all the paradoxes encountered by BBCM. It is very interesting to me that Einstein had reached the same conclusion: "The religion of the future will be cosmic religion. The religion, which is based on experience, which refuses dogmatic. If there's any religion that would cope the scientific needs, it will be Buddhism..." [14].

However, I don't think Einstein fully understood Buddhism and he was fundamentally still a believer of materialism since all the sciences he learned at that time were implicitly based on materialism. Otherwise, he should not lose the debate to Bohr in the explanation of the quantum phenomena [15]. The reason why Einstein mentioned Buddhism because he admired Spinoza. Spinoza's concept of religion is considered as pantheism. Pantheism is alien to European cultural sphere and is more appropriate to relate to Buddhism, which is not based on the concept of personal God at all. "Einstein was from the very youth inclined to question unquestionable, suspect self-evident, test trivial. His ideas on space (commensurability) and time (simultaneity), put into the formulae that will be called Special Theory of Relativity, were fruit of some five years meditations, as recognized by Einstein himself" [16].

\section{A Brief Introduction to BCM}

Every cosmological model needs the concepts of space and time. In BCM, it is specifically emphasized that all concepts or theories including space and time are created by our human beings and they are only of meaning to our human beings and no other types of life. Human beings are accustomed to describing any phenomenon in the space-time framework. We adopt the same definitions for space and time as BBCM which was provided by Kant: "Space and time are the framework within which the mind is constrained to construct its experience of reality" Kant [17].

Different from BBCM which assumed matter is the fundamental substance in nature, BCM assumes that energy is the fundamental essence of the universe. The universe consists of two types of energy, explicit energy and dark energy. Dark energy is defined as the essence of a life corresponding to the alaya consciousness in Buddhist theory $[18,19]$, it has the capability to accumulate the explicit energy into matter and decompose the matter into explicit energy. Explicit energy is the lifeless energy which can be accumulated by the alaya consciousness to be explicit matter or dark matter and then to bodies or objects. The level can be sensed by our human beings is defined as the explicit matter and the rest is defined as the dark matter.

Both explicit energy and dark energy in the universe always exist and satisfy the conservation law, but not the matter. This is the fundamental assumption made in BCM. Through this assumption, the awkward questions of the origins of life and matter in the universe can be avoided. All matter is accumulated by the dark energy (the alaya consciousness). This answers how the first matter comes from and the source of all types of forces in the universe which cause all the movements and changes of the universe. However, it must be emphasized here that what we have observed by our eyes are only small part in the world we are living and not the whole universe.

In the BBCM, it is very clear that the universe is finite in time but unclear whether it is finite or infinite in space. In the present $\mathrm{BCM}$, it is specifically defined that the universe is of infinite nature in both space and time. The world is defined of finite nature in both space and time and their relationship is expressed by the following equation: 


\section{Annals of Social Sciences \& Management studies}

$$
\text { Universe }=\sum_{i=1}^{\infty} \text { World }_{i}
$$

Each world is cyclically operated according to the process of formation, the steady state, deterioration and explosion to emptiness. In BCM, the Big Bang is the origin of the world we are living but not the universe. Using this definition, the awkward question of the origin of the universe can be avoided.

According to Buddhist philosophy [18,19], there are three types of life in the universe, the alaya consciousness only, the alaya consciousness with an insensible body (also dark matter to our human being) and the alaya consciousness with a sensible body (being animals and human beings) and these three types of lives can also be divided into six categories according to their happiness, Heaven, Asura, Human being, Animal, Ghost, Hell. Only human beings and animals are with a sensible body by our human beings. Non-existence of other types of lives is also a belief or an over-claim rather than a scientific proof. Lives with only the alaya consciousness only exists in the Heaven, they are the highest level of life in the universe while the lives in the Hell is the lowest level in the universe. So according to this BCM [7], human beings are not the most intelligent creatures in the universe but in the middle level. All the matter used by other four types of lives and together with their bodies belong to dark matter.

Everything in the universe including all the worlds and each individual life is operated according to the Causal-Effect law. This can be regarded as the second assumption of this BCM. For any lifeless object in the world we are living, no matter whether we can see (explicit matter) or not (dark matter), it will experience the cycle of formation, the steady state, deterioration and destroy and for each individual life, no matter whether we can see (human beings and animals) or not (other four types of lives), she/he will be reincarnated within the six types of lives in the universe. Here it must be pointed out that according to the causal-effect law, reincarnation of my live is not confined to this world I am living, but in the whole universe. Even for the alaya consciousness only life in the Heaven, she/he will also have a life span and can be reincarnated into other five types with a body in the universe, not necessarily in the same world as he/she lived in a previous life. Reincarnation of all lives is a law of nature [20]. So, in this BCM, parents provide only the bodies to their children and not the life. We are very soon reached a stage that we can clone our bodies, but the essence of life does not change, and any lives produced this way should have the same rights as us.

Human's consciousness includes 8 types, they are consciousness at eyes, ears, nose, tongue, body and mind, the manas consciousness, and finally the alaya consciousness. When one is dying the consciousness at eyes, ears, nose, tongue, body and mind will be lost. The function of the seventh consciousness whose formal name is called the manas consciousness, is the bridge between the former six consciousness with the eight whose formal name is called the alaya consciousness. Only the alaya consciousness will continue to exist and it is the source of life forces and it stores all the karmas in the previous life history. The dying process is a process of the separation of the alaya consciousness with the body. For the detailed theory of Buddhism, one can refer to references $[18,19]$.

\section{A Comparison of $\mathrm{BCM}$ with $\mathrm{BBCM}$}

Now let us compare these two models' item by item and they are listed in (Table 1). From this comparison, one can see that BCM gives clear definitions to all the main concepts used while in BBCM most of concepts are unclearly defined and the conservation laws thus used are fundamentally wrong. For example, matter conservation and momentum conservation should not be the general rules and may be valid for a very limited range. The energy conservation also needs to consider the contribution from dark energy. Without the participation of dark energy, no reaction or transformation from energy to matter or from matter to energy is possible. No matter accumulating energy into matter or decomposing matter into energy, it must have the participation of dark energy. Therefore, Einstein's famous equation should be modified as

$$
m C^{2}=E+E_{\text {dark }}
$$

\begin{tabular}{|c|c|c|}
\hline Item & ВBCM & BCM \\
\hline Concept of space and time & Same definition of Kant's [17] & Same definition of Kant's [17] \\
\hline Definition of Universe & $\begin{array}{l}\text { Unclear of infinity in space and } \\
\text { finite in time }\end{array}$ & Clear definition of infinity in both space and time \\
\hline Essence of Universe & Matter & Energy \\
\hline Definition of world & $\begin{array}{l}\text { No distinction between universe } \\
\text { and world }\end{array}$ & Clear distinction of universe and world as two different concets. \\
\hline Definition of matter & Unclear & Clear definition of explicit matter and dark matter. \\
\hline Definition of consciousness & Unclear & $\begin{array}{l}\text { Human's consciousness includes } 8 \text { types and only the alaya consciousness will } \\
\text { continue to exist and it is the source of life forces and it stores all the karmas in } \\
\text { the previous life history. The dying process is a process of the separation of the } \\
\text { alaya consciousness with the body. }\end{array}$ \\
\hline Definition of dark matter & $\begin{array}{l}\text { Unclear, causing difficulty in } \\
\text { finding. }\end{array}$ & $\begin{array}{l}\text { All matter was accumulated by dark energy. The level can be sensed by our } \\
\text { human beings is defined as the explicit matter and the rest is defined as the dark } \\
\text { matter. }\end{array}$ \\
\hline
\end{tabular}

Table 1: A brief comparison of BCM with BBCM on fundamental issues. 
Annals of Social Sciences \& Management studies

\begin{tabular}{|c|c|c|}
\hline Definition of dark energy & $\begin{array}{l}\text { Unclear, no clue how to prove its } \\
\text { existence }\end{array}$ & $\begin{array}{l}\text { Dark energy is defined as the essence of a life corresponding to the alaya } \\
\text { consciousness in Buddhist theory. }\end{array}$ \\
\hline Deterministic/probabilistic & $\begin{array}{l}\text { Macro world is deterministic } \\
\text { (General Relativity Theory) while } \\
\text { micro world is probabilistic } \\
\text { (Quantum Mechanics). }\end{array}$ & $\begin{array}{l}\text { Fundamentally, the universe including macro and micro worlds always works } \\
\text { regularly or with rules, and these rules can always be revealed by us humans. } \\
\text { Practically, due to the complexity of the actual problem and the time limit of our } \\
\text { human life, we may not be able to reveal the real rules of the world operation in } \\
\text { our lifetime, especially it is hard for us to identify all the influencing factors. There } \\
\text { always exists hidden variables, probability theory can be applied to improve the } \\
\text { prediction reliability under uncertainty [22]. }\end{array}$ \\
\hline Knowability & $\begin{array}{l}\text { Philosophically agnosticism but } \\
\text { practically always seeking some } \\
\text { operational rules. Paradoxical } \\
\text { behavior. }\end{array}$ & $\begin{array}{l}\text { The causal-effect law for everything can be knowable and two independent } \\
\text { methods exist, one is the knowledge acquisition and the other is meditation. The } \\
\text { rule about the movement of the alaya consciousness can only be known through } \\
\text { meditation. }\end{array}$ \\
\hline Definition of life & Unclear. & $\begin{array}{l}\text { There are three types of life in the universe, the alaya consciousness only, the } \\
\text { alaya consciousness with an insensible body (also dark matter to our human } \\
\text { being) and the alaya consciousness with a sensible body (being animals and } \\
\text { human beings). }\end{array}$ \\
\hline Operation of life & $\begin{array}{l}\text { Only one term and randomly } \\
\text { operated. }\end{array}$ & $\begin{array}{l}\text { For each individual life, no matter whether we can see (human beings and } \\
\text { animals) or not (other four types of lives), she/he will be reincarnated within the } \\
\text { six types of lives in the universe. Reincarnation of all lives is a law of nature [20]. }\end{array}$ \\
\hline Conservation law & $\begin{array}{l}\text { Energy conservation, matter } \\
\text { conservation and momentum } \\
\text { conservation }\end{array}$ & Only energy conservation $\mathrm{mC}^{2}=\mathrm{E}+\mathrm{E}_{\text {dark }}$ \\
\hline
\end{tabular}

It is obvious that the requirement of $E_{\text {dark }}$ is different for different substance.

Different from the materialist world view, the essence of the universe is not matter but energy. There are basically two types of energy, one is the explicit energy which is the essence of all matter, no matter explicit matter which we can see or feel or the dark matter which we cannot see or feel, and the other is dark energy which is the essence of life. This is called the alaya consciousness in the Buddhist philosophy. With this BCM model, it avoids many awkward questions related to the origin of universe and life in the universe and it answers the important questions of the origin of matter and the source of forces behind. It has automatically revealed the most difficult part of modern physics about dark matter and dark energy. It can easily explain many other phenomena in the world we have observed. To my own knowledge, this model seems to be able to explain all the anomalous phenomena mentioned in Ref. [4]. The detail can be found in Ref. [7].

I think Buddhist philosophy is better than materialism to act as the scientific foundation for modern sciences and it can eliminate many difficulties faced in many disciplines of modern sciences. I am particularly welcome all the criticisms to BCM. If $\mathrm{BCM}$ can stand in comparison with BBCM, it may be a time to consider the end of materialism and update the modern sciences on the Buddhist philosophy.

In a recent paper in PNAS, authors addressed the importance of philosophy to science and from their perspective, philosophy's contribution to science can be found at least from four aspects: "the clarification of scientific concepts; the critical assessment of scientific assumptions or methods; the formulation of new concepts and theories; and the fostering of dialogue between different sciences, as well as between science and society" [21]. This is a very rare but important opinion I found nowadays and most of the present-day scientists often perceive philosophy as completely different from, and even antagonistic to, science. While the present author fully agrees with these opinions, I wish to bring the discussion a step further. It is really the time for us to consider seriously what philosophy should modern sciences need?

\section{Summary and Conclusion}

All the modern sciences are based on the materialism which are critically questioned nowadays [5,6]. The most important representation of modern sciences is the Big-Bang Cosmological Model (BBCM) and this model has been confronted to a variety of observations which are called paradoxes. In order to resolve these paradoxes, a novel cosmological model based on Buddhist philosophy (BCM) was recently proposed by the present author and in the present paper a detailed comparison between these two models has been carried out. Through this comparison, the following conclusions can be drawn [22,23].

a) The fundamental reason for most of paradoxes related to materialism or BBCM is due to the unclear definitions of many fundamental concepts, such as universe, world, matter and consciousness.

b) The essence of universe should be defined as energy rather than matter and it can avoid many awkward questions related to the origin of universe and life in the universe and it answers the important questions of the origin of matter and the source of forces behind.

c) There are basically two types of energy, one is the explicit energy which is the essence of all matter, no matter explicit matter which we can see or feel or the dark matter which we cannot see or feel, and the other is dark energy which is the essence of life. This is called the alaya consciousness in the Buddhist philosophy. 


\section{Annals of Social Sciences \& Management studies}

d) The energy conservation is the only law which can be assumed but it needs to consider the contribution from dark energy. Without the participation of dark energy, no reaction or transformation is possible. No matter accumulating energy into matter or decomposing matter into energy, it must have the participation of dark energy.

e) It seems that BCM is conceptually clear and logically consistent and it can explain many phenomena which belongs to the frontier problems of modern sciences. It may be the time to seriously consider replacing materialism by Buddhist philosophy to act as the scientific foundation for modern sciences and it could eliminate many difficulties faced in many disciplines of modern sciences, especially life science.

\section{Acknowledgement}

This work was supported by the State Key Program of National Natural Science of China "Structural Reliability Analysis on the Spherical Hull of Deepsea Manned Submersibles" (Grant No. 51439004), the General Program of National Natural Science of China "A study on the water absorption property of the buoyancy material for the full ocean depth manned submersible" (Grant No. 51879157), the "Construction of a Leading Innovation Team" project by the Hangzhou Municipal government, the Startup funding of New-joined PI of Westlake University with grant number (041030150118).

\section{References}

1. Uzan, Jean-Philippe (2015) The Big-Bang Theory: Construction, Evolution and Status L'Univers, S'eminaire Poincar'e XX: 1-69.

2. Arun K, Gudennavar SB, Sivaram C (2017) Dark matter, dark energy, and alternate models: a review. Advances in Space Research 60: 166186

3. Burago, SG (2017) About the theory of the Big Bang, The General Science Journal. Astrophysics. pp. 1-7.

4. Moreira-Almeida A, Santos, FS (2012) Exploring Frontiers of the MindBrain Relationship, Springer, New York, Dordrecht Heidelberg, London.

5. Sheldrake, R (2012) The Science Delusion Freeing the Spirit of Enquiry. Coronet, An imprint of Hodder \& Stoughton, A Hachette UK company, UK.

6. Tart, CT (2009) The End of Materialism: How Evidence of the Paranormal Is Bringing Science and Spirit Together, New Harbinger Publications, Inc, Oakland, USA.

This work is licensed under Creative Commons Attribution 4.0 License DOI: 10.19080/ASM. 2019.03.555612
7. Cui WC (2019a) On A Logically Consistent Cosmological Model Based on Buddhist Philosophy, Ann Soc Sci Manage Stud 3(1): 555605.

8. Salmon WC (1970) Zeno's Paradoxes Bobbs-Merrill, New York, USA.

9. Sarfati JD (1998) If God Created the Universe, Then Who Created God? CEN Tech J 12(1): 20-22.

10. Zwiebach B (2004) First Course in String Theory, Cambridge University Press, USA.

11. Schramm DN (1998) The age of the universe, dark matter, and structure formation. Proc Natl Acad Sci USA 95: 1.

12. Wilczek F (1982) Old and new relics in cosmology (A Review). Proc Natl Acad Sci USA 79: 3376-3379.

13. Bahcall NA (2015) Dark matter universe. Proc Natl Acad Sci USA 112(40): 12243-12245.

14. Einstein A (1930) "Religion and Science", New York Times Magazine, November 9, 1930, cited from Einstein A (1954) "Ideas and Opinions", Crown Publishers, New York.

15. Cui WC, Kang BL (2008) Examining the debate between Einstein and Bohr based on Buddhist philosophy. Journal of Chinese Social Sciences 55(8): 1-9.

16. Dokovic V, Grujic P (2007) Albert Einstein, Cosmos and Religion. Serb Astron J 174: 61-72.

17. Kant I (2002) Metaphysical Foundations of Natural Science, in Theoretical Philosophy after 1781, edited by Henry Allison and Peter Heath, translated by Michael Friedman, Cambridge University Press, Cambridge.

18. Laumakis, Stephen J (2008) An Introduction to Buddhist Philosophy. Cambridge University Press, New York, USA.

19. Harvey P (2013) An Introduction to Buddhism, Teachings, History and Practices, $\left(2^{\text {nd }}\right.$ edn $)$, Cambridge University Press, Cambridge, New York, Melbourne, Madrid, Cape Town, Singapore, São Paulo, Delhi, Mexico City.

20. Das S (2013) Reincarnation-a Law of Nature. International Journal of Modern Engineering Research (IJMER) 3(2): 1192-1211.

21. Laplane L, Mantovanic P, Adolphs R, Chang H, Mantovani A, et al. (2019) Why science needs philosophy. Proc Natl Acad Sci USA 116(10): 39483952.

22. Cui WC (2019b) A Simple Idea on the Unification of Einstein-Bohr Controversy. Ann Soc Sci Manage Stud 2(5): 555597.

23. Wilczek F (2005) Asymptotic freedom: From paradox to paradigm, Proc Natl Acad Sci USA 102(24): 8403-8413.

\section{Your next submission with Juniper Publishers} will reach you the below assets

- Quality Editorial service

- Swift Peer Review

- Reprints availability

- E-prints Service

- Manuscript Podcast for convenient understanding

- Global attainment for your research

- Manuscript accessibility in different formats

( Pdf, E-pub, Full Text, Audio)

- Unceasing customer service

Track the below URL for one-step submission https://juniperpublishers.com/online-submission.php 